\title{
ANÁLISIS DE ELEMENTOS CONSTRUCTIVOS EN SANTA EULALIA DE MÉRIDA-ESPAÑA
}

\author{
(ANALYSIS OF CONSTRUCTION ELEMENTS OF SANTA EULALIA, MÉRIDA-SPAIN)
}

Luis Caballero Zoreda y Santiago Feijoo Martínez

Dep. Historia Antigua y Arqueología, CEH.-CSIC.

Fecha de recepción: 13-III-95

ESPAÑA

\section{RESUMEN}

En la iglesia de Santa Eulalia de Mérida, donde según las fuentes antiguas estuvo enterrada la mártir emeritense que le da nombre, se aplicó el método de lectura de paramentos a los restos constructivos que aparecieron en la excavación de su subsuelo. Se decidió usar este método ya que la excavación propiamente dicha no habia llegado a resultados satisfactorios, por la ausencia de contextos coetáneos a la utilización de los restos constructivos que, además, aparecieron profundamente destruidos. Sin embargo la lectura de paramentos permitió ordenar los procesos de construcción, restauración y destrucción de estos restos en una completa secuencia que abarca desde comienzos de la Era hasta prácticamente nuestros días.

\section{SUMMARY}

In the church of Santa Eulalia in Mérida where, according to ancient sources, the Merida martyr was buried, the stratigraphic method was applied to the construction remains which appeared in the excavations of the subsoil. This method was chosen because the excavation itself had not led to satisfactory results, due to the absence of contexts contemporary with the use of the construction remains which, in addition, turned out to be badly damaged. Nevertheless, the stratigraphic method allowed the processes of construction, restoration and destruction of these remains to be ordered into a complete sequence which spans the period from the beginnings of the Christian era to our days.
Los trabajos arqueológicos en Santa Eulalia de Mérida comenzaron a principios de 1990 , propiciados por la intención del párroco de renovar el pavimento de la iglesia. Se iniciaron como una mera excavación de urgencia, pero pronto se comprobó la complejidad del yacimiento debido a dos razones: la ausencia de niveles arqueológicos y el aparente caos de cimientos (Fig.1). Estos aparecían como fragmentos de muros arrasados y sin relación directa entre sí, debido a los enterramientos que se efectuaron, sin interrupción y hasta el terreno firme, desde época paleocristiana hasta la construcción del cementerio municipal de Mérida en 1837. Con la excavación prácticamente terminada, se creyó que la única solución plausible para ordenar estos restos y conseguir unas conclusiones históricas válidas era intentar su análisis utilizando el "método Harris" (1991), según lo han desarrollado para su aplicación a la arquitectura los italianos Parenti (1985) y Brogiolo (1987-88). Sin embargo hay que acentuar el carácter especial del objeto de estudio, ya que no puede considerarse propiamente ni una excavación arqueológica, por la ausencia de contextos, ni un edificio en pie, por la ausencia de muros en altura y cerrados entre sí formando habitaciones. Las dificultades por lotanto eran extremas, pero sirvieron para lograr un desarrollo especial del método y para demostrar su facultad para resolverlas. En este trabajo nos vamos a centrar en las características específicas de esta lectura.

Sta. Eulalia es una iglesia situada en lo que eran los arrabales de Mérida, que tradicionalmente se relaciona con 
el lugar donde estuvo enterrada la mártir Eulalia. Su fábrica, de apariencia románica con tres naves rematadas en ábsides, no se había considerado de interés, salvo por la presencia de capiteles romanos reutilizados, y apenas se había aducido la posibilidad de que los muros de su cabecera pertenecieran a una basílica primitiva (Bueno 1987), a pesar de las indudables referencias documentales del $\mathrm{s}$. VII a una importante basílica funeraria que formaba conjunto con un monasterio y otros edificios (como informan las Vitas Sanctorum Patrum Emeretensium, edit. Maya 1992). La superficie interior analizada es de $49,90 \times 19,70$ $\mathrm{m}$, a la que hay que añadir la de los muros en alzado con una longitud aproximada de $89 \mathrm{~m}$. El trabajo desarrollado fue la primera experiencia de nuestro equipo, que intervino con una media de seis personas durante tres meses, dividido en dos campañas, diferenciando 1004 elementos o fichas.

La imposibilidad de diferenciar al primer golpe de vista los conjuntos de restos que eran similares entre sí y de definir las relaciones existentes entre ellos, hizo que se sistematizara el proceso desde el principio lo más posible. Para esto primero se dividió el espacio de la iglesia en 55 zonas arbitrarias (Fig.2), que se consideraron unidades de análisis completamente independientes, de modo que los equipos, formados por parejas de analistas, tuvieran un campo de trabajoabarcable que, a su vez, les aislaba psicológicamente de la problemática general del yacimiento. Pero, desde el inicio, las zonas se solaparon entre sí de modo que se analizaran en las zonas vecinas unos mismos elementos

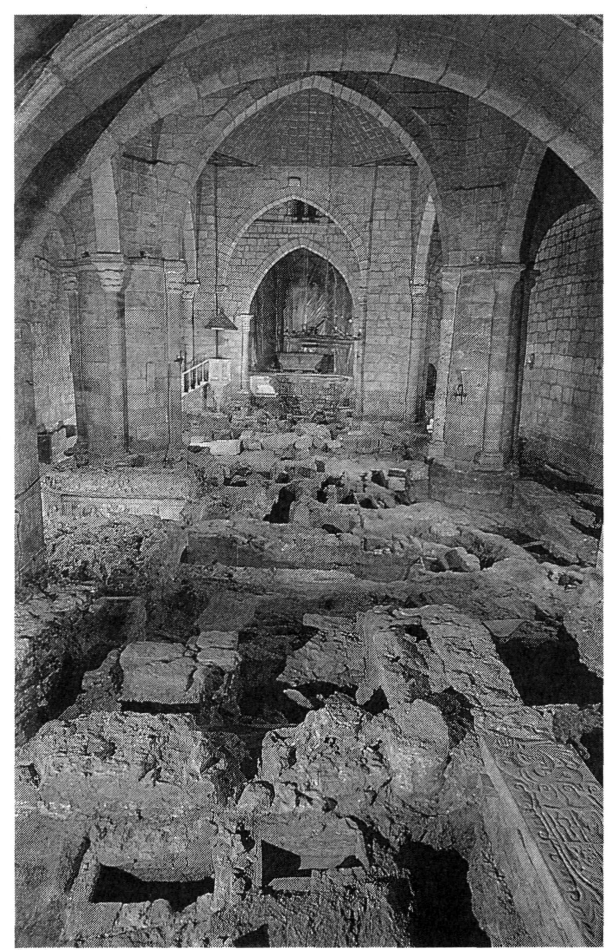

Fig.1.- Interior de la iglesia de Sta. Eulalia de Mérida una vez terminada la excavación arqueológica. situados en sus bordes, que servirían después como elementos de conexión al contrastar o correlacionar las zonas entre sí y sintetizar sus conclusiones. En la cabecera de la iglesia se consideraron también como zonas sus muros, allí donde se observó que pertenecían a la basílica paleocristiana y alto medieval.

A cada zona correspondía un croquis de trabajo (Figs. 4 y 7) donde se diferenciaban gráficamente los elementos. La diferenciación de los elementos estratigráficos en los cimientos aparecidos en la excavación presentaba una gran dificultad, dado su grado de destrucción y que se habían utilizado una y otra vez con distintas funciones constructivas, integrándose, por ello, en unidades

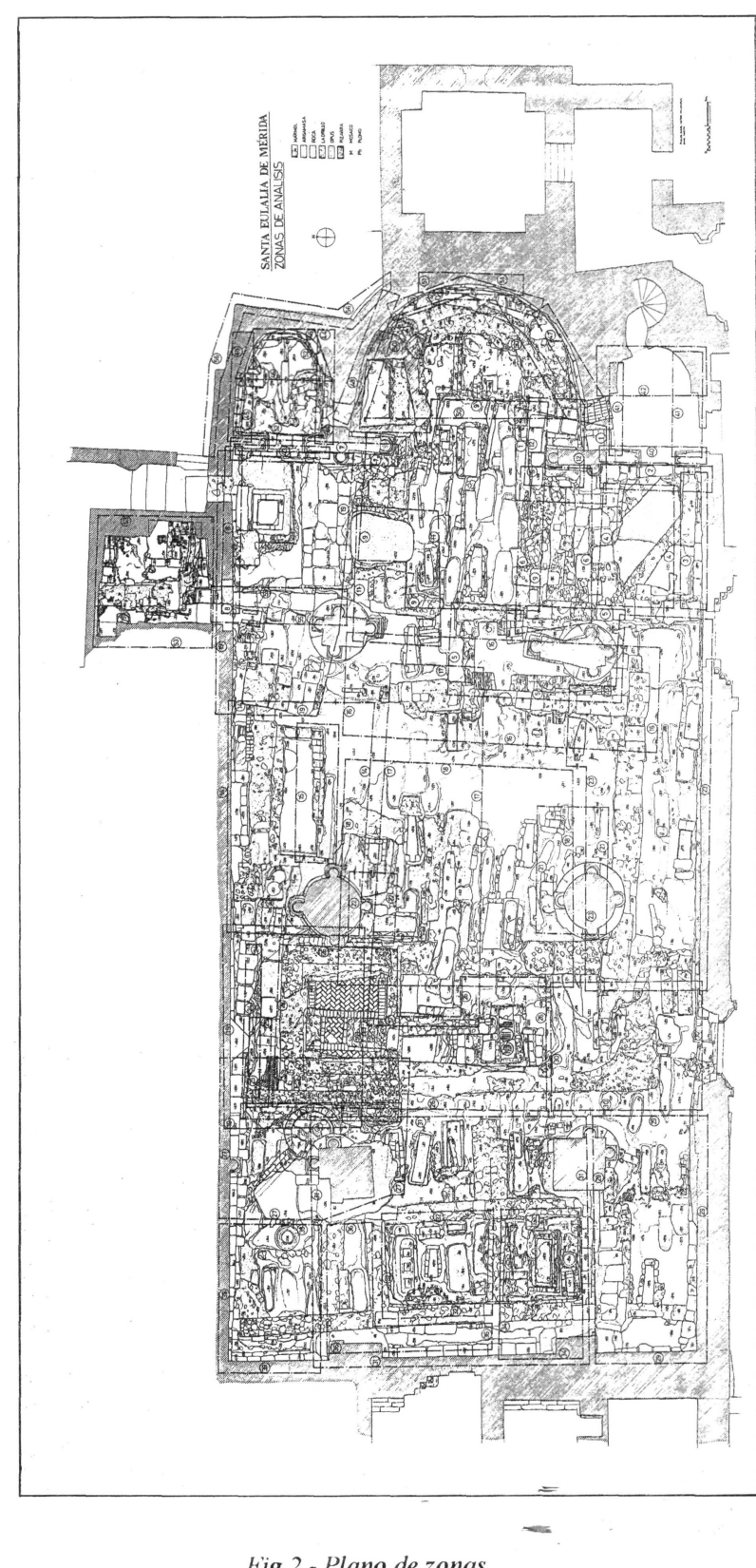

Fïg.2.- Plano de zonas. 


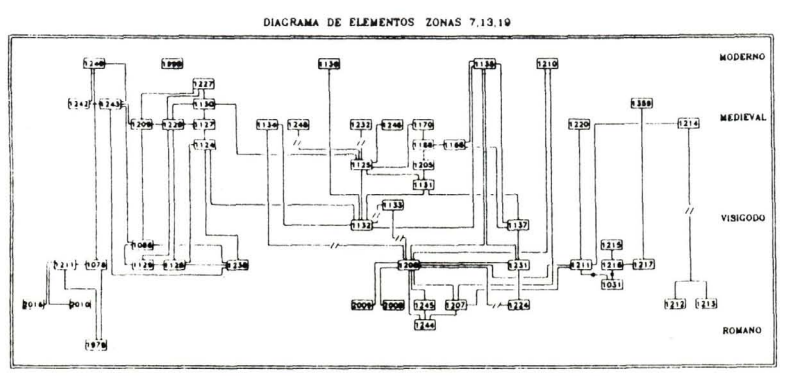

Fig.5.- Diagrama correspondiente a las zonas 7,13 y 19. Sin reducir las relaciones redundantes.

posteriores. Para diferenciarlos se atendió a los siguientes criterios: su situación topográfica, distinguiendo como elementos diferentes aquellos que estaban en zonas distintas o que no unían entre sí; el tipo de material y aparejo que los componían; sus soluciones de continuidad o límites; y su finalidad constructiva o funcional. Como criterio general se aceptó que la menor duda sobre la similitud de dos unidades bastaría para diferenciarlas.

Unido al problema de la diferenciación de elementos estaba el de las denominadas entonces por nosotros soluciones de continuidad-interfaces en la terminología de Harris, o discontinuidades en la geológica-. Aunque cumplían un papel fundamental para diferenciar los elementos, era imposible periodizarlas por las causas ya citadas de la descontextualización y la destrucción sistemática. Además cada elemento tenía una media de seis soluciones de continuidad, y el haberlas tenido en cuenta hubiera supuesto trabajar entre cuatro y seis millares más de unidades, en su mayoría inútiles ya que, como hemos dicho, era imposible datarlas y ni siquiera adscribirlas a

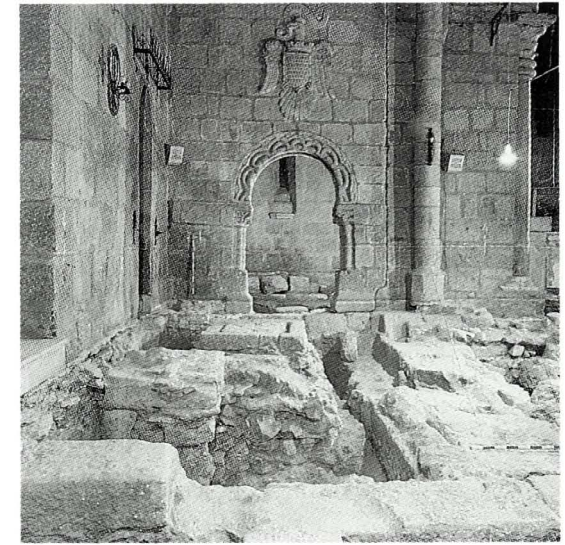

Fig.3.- Vista general y detalle de las "superficies de corte" en forma de cara de muro y de columna románica, tallando el muro de la basílica paleocristiana del que se ve delante su cimiento. Entrada a la capilla delantera $N$. Zonas 7 y 19.

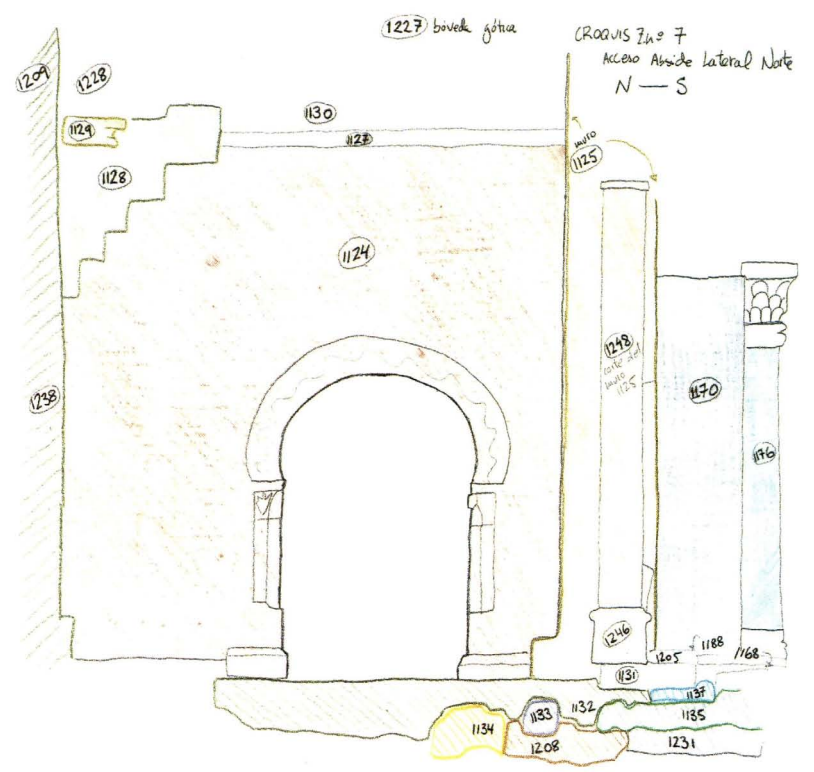

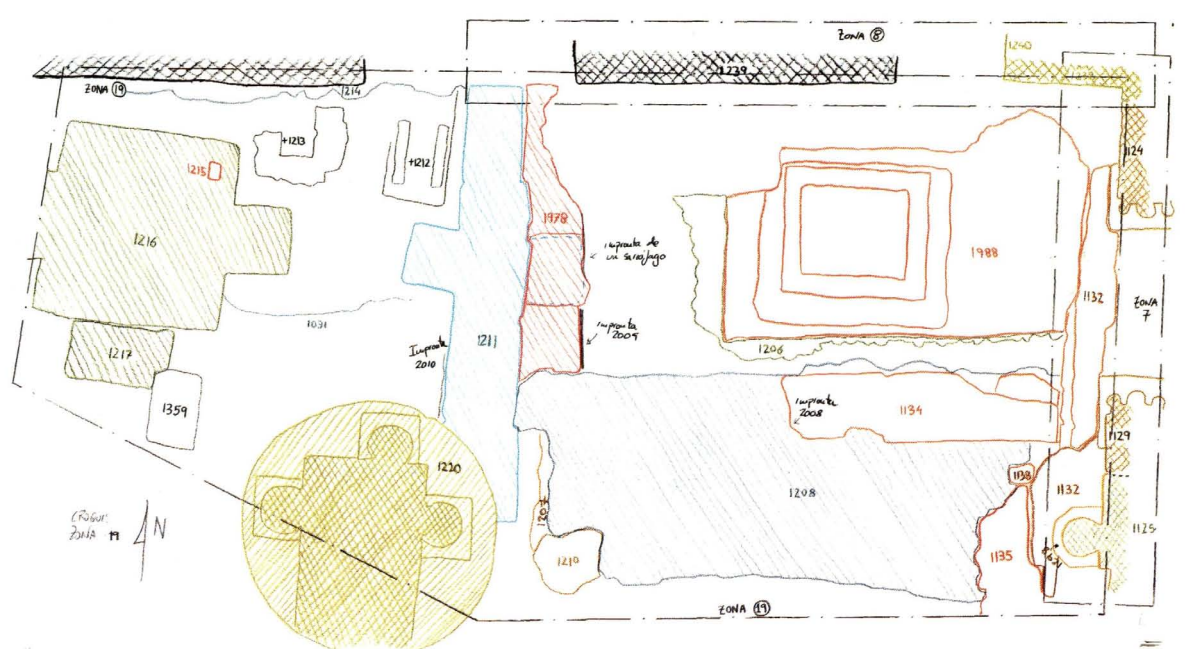

Fig.4.- Croquis de las zonas 7 y 19, entrada a la capilla $N$., con el muro paleocristiano (E1125) y su cimiento (E1131, 1132, 1137, 1168, 1205,1208 y 1231) cortados por la obra románica (cara de muro E1124, basa E1246 y fuste E1248). 


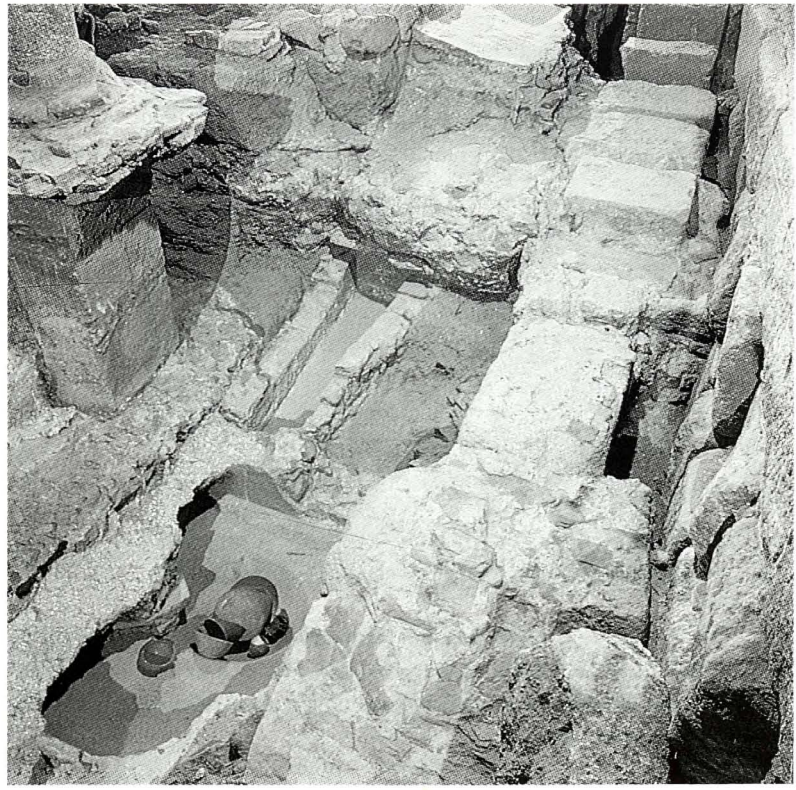

Fig.6.- Un ejemplo de lectura de relaciones. La pileta de baño E1281 = Est1) de la primera casa romana se amortizó -hacia el año 40 dC. según la cronología de los objetos abandonados en ella- ,cubriéndose con el hormigón de suelo $(E 1280,1278=$ Est9) del patio dela segunda casaque, en el s. $I V$, fue cortada por una sepultura de ladrillos (E1291 = sep37). Ésta fue sobremontada enseguida por los cimientos de hormigón del mausoleo absidado (E1292 y 1401 = Est31, al fondo ). Todos estos elementos fueron cortados, a su vez, en el s. VI, por el cimiento de la arcada N.de la basílica paleocristiana (E1270=Est 37 , a la derecha) y, finalmente, por el muro $N$. y uno de los pilares de la actual iglesia (E1285 y 1279, a la derecha e izquierda). Zona 14. algún período histórico. Por ello se decidió no tenerlas en cuenta, conscientes de que esta medida iba contra el método, pero de acuerdo con el principio de que el método es auxiliar y por lo tanto debe adaptarse a los problemas del yacimiento, y no al contrario. De todos modos se mantuvo, como excepción, la norma de diferenciar y numerar las soluciones de continuidad sólo cuando reflejaran una acción con valor cronológico o funcional de interés.

Como ejemplo más claro tenemos en las zonas 7 y 19 , una aparente columna románica en la entrada a la capilla delantera N. (Figs. 3-5). El proceso histórico de su construcción fue el siguiente: la cabecera de la basílica paleocristiana teníaun santuario muy profundo que ocupaba el ábside y el tramo delantero de la iglesia actual y que se separaba, mediante gruesos muros, de sendas habitaciones laterales que funcionaban como sacristías (Fig. 16A). Con el abandono de la iglesia en época musulmana estos muros debieron arruinarse y, en último extremo, fueron cortados por los restauradores románicos que así sustituyeron la cabecera primitiva por la actual de tres ábsides. Entonces descargaron los arcos formeros del primer tramo en los arruinados muros primitivos, retallando sus cortes en forma de columnas adosadas, de modo que éstas no corresponden a verdaderos elementos sino a soluciones de continuidad o meras superficies que cortan y "esculpen" la materia perteneciente al muro paleocristiano. Por lo tanto se debe diferenciar el elemento (E1125, muro paleocristiano

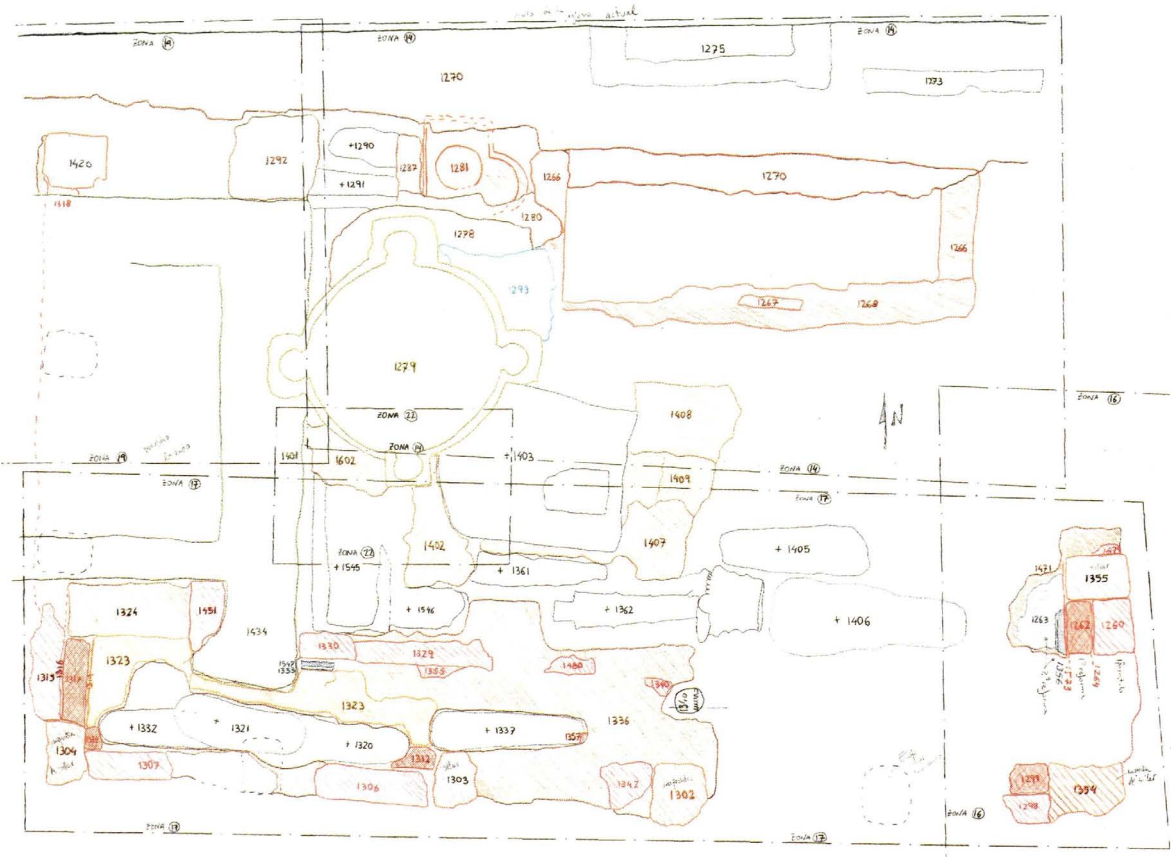

Fig.7.- Croquis de elementos de las zonas 14, perteneciente a la pileta de la primera casa romana (Fig.5), y 17 y 18 , al peristilo de la segunda casa romana (Figs. 7 a 9).

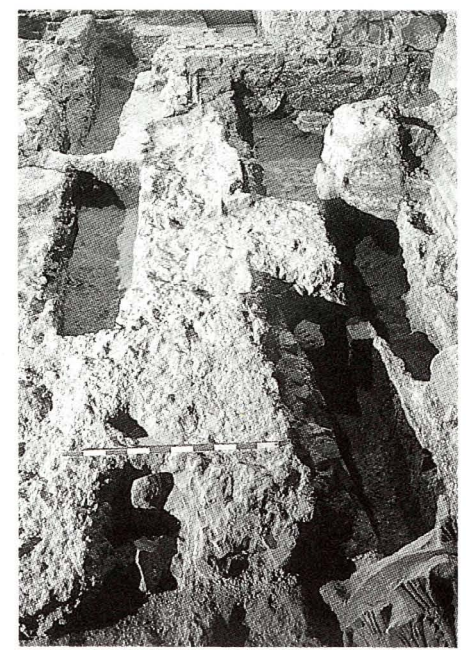

Fig.8.- Vista desde E.de la infraestructura de hormigón (E1336) del suelo del patio de la segunda casa romana (Est9), que monta sobre un muro previo (E1340 =Est 8 , en primertérmino) y cortada por sepulturas paleocristianas y medievales. Al fondo, le atraviesa el mausoleo absidado (E1434 = Est31). 


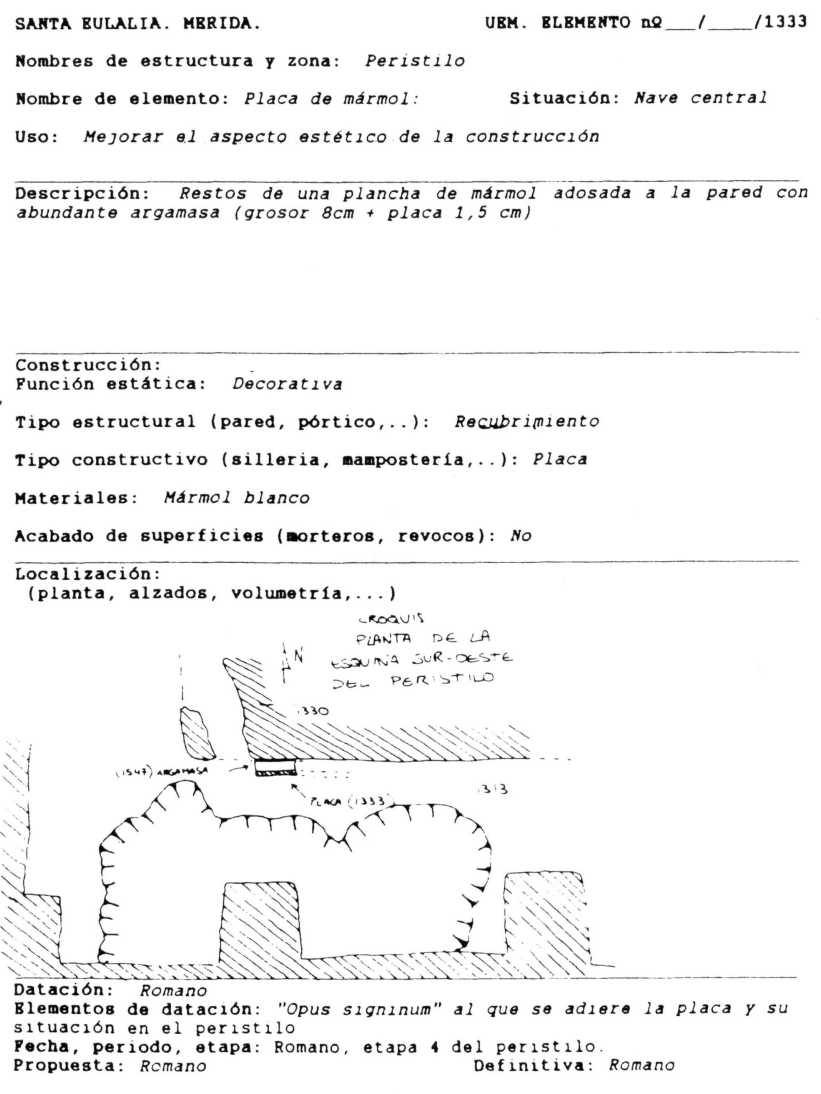

\begin{tabular}{|c|c|c|}
\hline \multicolumn{2}{|c|}{$\begin{array}{l}\text { (UBM. Blemento. Trasera) } \\
\text { Relaciones ostrat igrafficas: }\end{array}$} & 14341446 \\
\hline Apoya on: 1313 & So 10 apoya: 1434,1646 & \\
\hline Corta a: & Cortado por: 1434 & 1332 \\
\hline Se une a : & Igual a: 1508,1356 & L \\
\hline Cubre a: & Cubierto por: & $1508=1333=1356$ \\
\hline Be adosa a: 1547 & 80 10 adosa 1332 & 马 \\
\hline $\begin{array}{l}\text { Rolaciones indire } \\
\text { consistentes on: }\end{array}$ & : 1356,1319 & 1547 \\
\hline
\end{tabular}

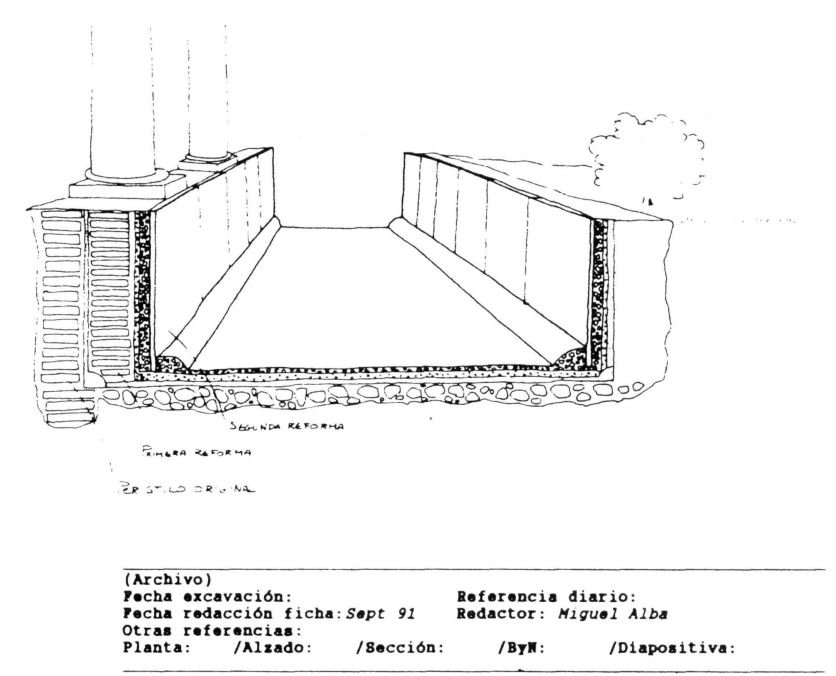

Fig.9.- Ficha de elemento. Placado de mármol (E1333, Fig.8) con que se restauró el peristilo de la segunda casa romana (Est9).

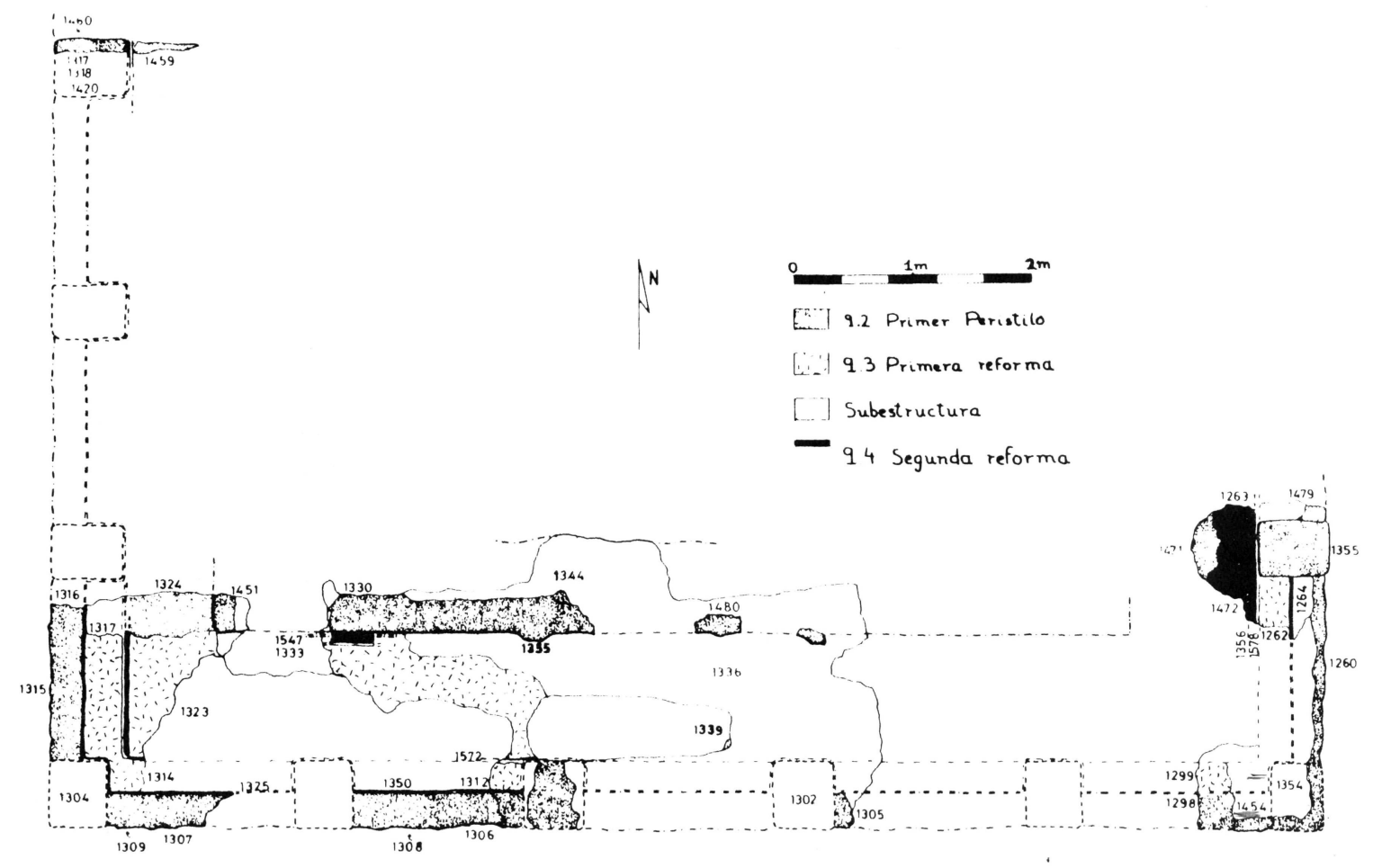

Fig.10.- Croquis de la estructura 9, peristilo de la segunda casa romana.

(c) Consejo Superior de Investigaciones Científicas 


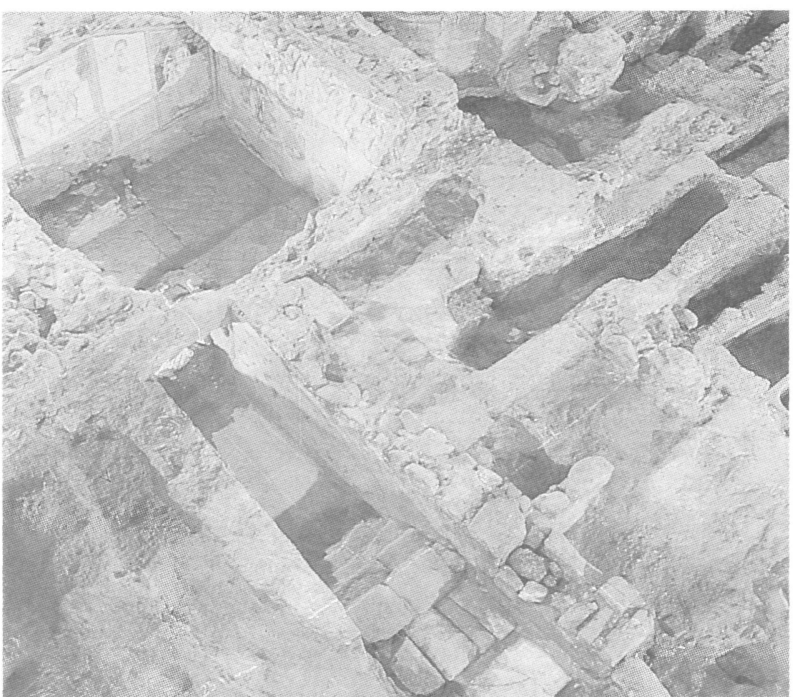

Fig.11.- Vista general, desde SO. , de la cripta del mausoleo absidado (Est31) con su escalera de acceso.

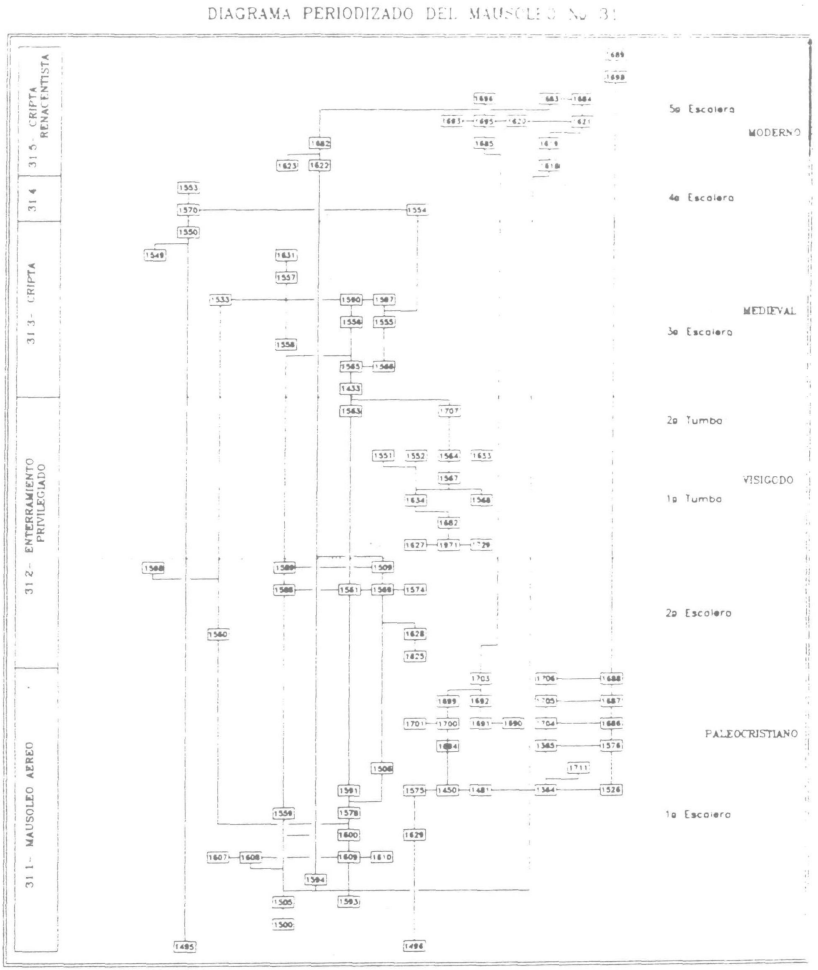

Fig.12.- Diagrama periodizado de los elementos que conforman del mausoleo absidado, estructura 31.

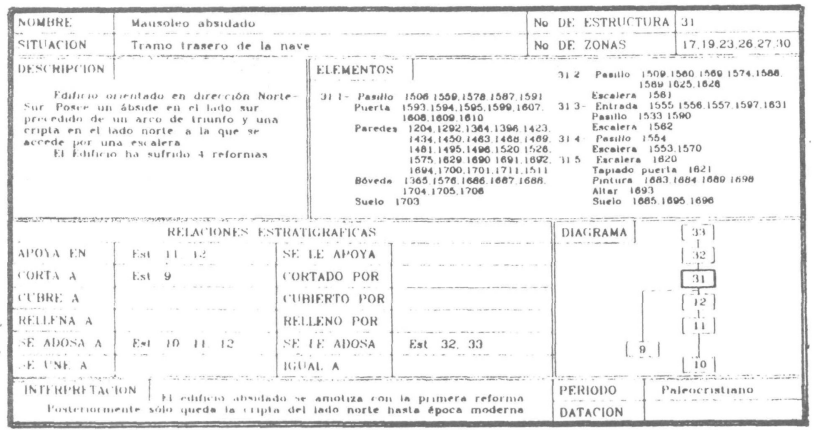

Fig.13.- Ficha de la estructura 31, mausoleo absidado.
N.) de su nueva superficie (E1124 cara, 1246 basa y 1248 fuste; lo mismo en el lado S.) datada perfectamente por su tipología. En resumen, se intentó simplificar todo lo posible la lectura, dada la abundancia de restos, pero siempre que no redundara en pérdida de información.

Otro de los problemas derivado de la especial característica del yacimientoanalizado surgióal diferenciar las relaciones existentes entre los elementos y registrarlos en las fichas. La diferenciación de las relaciones estratigráficas de carácter constructivo no es tan fácil como en un principio puede parecer, pues mientras que es evidente su relación espacial -un elemento al lado, encima o debajo de otro-, suelen plantearse dudas sobre cuál de los elementos actuó sobre el otro, qué actividad provocó esta situación y, en última instancia, en qué dirección temporal se dió la relación o, lo que es lo mismo, qué elemento es anterior y cuál posterior. Por ello, es fundamental llegar a un consenso sobre el significado concreto de las relaciones.

La relación se adosa/se le adosa, en contadas ocasiones se prestaba a discusión, pues era realmente difícil discernir qué elemento era el que se adosaba al otro, al haberla definido como un contacto vertical y efectuarse entre fragmentos de muros en los que no se podía decidir cuál era el más antiguo; pero, en sí, la relación es objetiva y el discernir o no su valor de antero/posterioridad responde a dicha limitación. Siempre que se daba esta duda se acompañaba por una interrogación y, si se decidía cuál era la dirección temporal precisa de la acción, se anotaba en el apartado de interpretación.

La relación se une/se le une podía tener dos significados diferentes: unir como una acción coetánea -igual a-; o unir como la acción de romper y trabar íntimamente un muro posterior a otro anterior. Nosotros optamos por el primero y consignábamos el segundo con las relaciones corta y se adosa que habrían estado implícitas en la segunda definición de unir. Elegir uno u otro significado, mientras no exista un consenso normativo, queda al criterio del investigador; de hecho, en trabajos posteriores hemos utilizadoel segundo.

La relación igual a se tomó literalmente y no como parecido o similar, pues éstos implican una interpretación subjetiva. Para ellos dispusimos un apartado de relaciones indirectas con, consistentes en.

Como las relaciones tenían una importancia decisiva para deducir conclusiones temporales y funcionales específicas, y dada su extrema complicación, se optó por analizar todas aunque fueran redundantes -el elemento $X$ puede cortar y a la vez apoyar sobre el $Y$-. Así se hizo tanto en los apartados de relaciones y de diagrama en las fichas, como en los diagramas de zonas (Fig.5). Para distinguirlas en los diagramas se inventaron grafismos específicos colocados en las líneas de unión, como se explica en el artículo de introducción: se adosa, la línea une lateralmente dos elementos; se apoya, va de la parte inferior de un elemento 


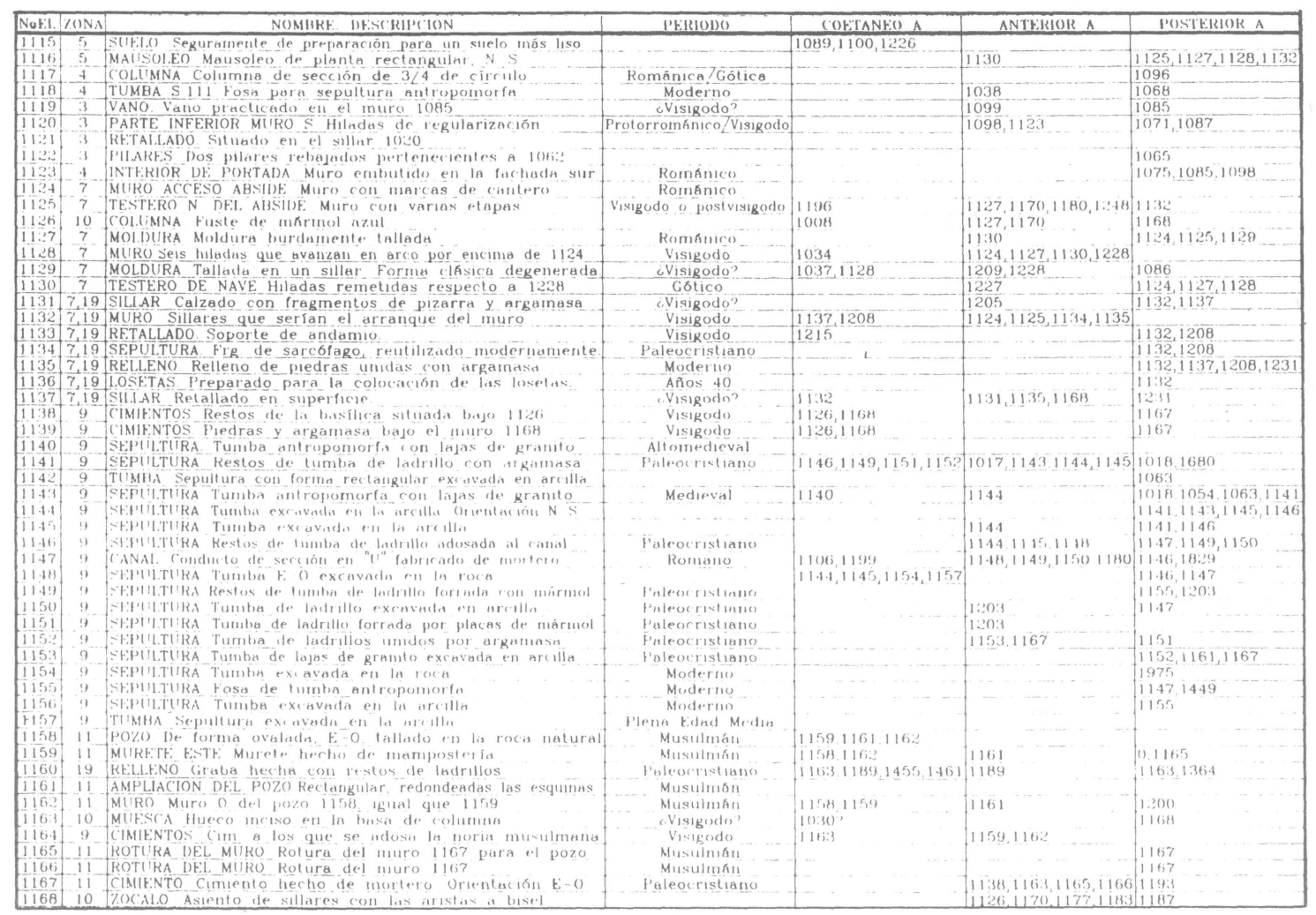

Fig.14.- Ejemplo de listado de elementos.

a la superior del otro; corta, mediante el símbolo(//); igual, con $(=)$; rellena, con (o); une, con los elementos a la misma altura y unidos lateralmente; relaciones indirectas, con líneas discontinuas (- - ); y relaciones dudosas, con una interrogación (-?-). De esta forma, a pesar de su relativa complejidad, era factible observar las posibles contradicciones en las que se podía caer durante la lectura y durante la misma realización del diagrama.

El dividir la excavación en zonas permitió realizar diagramas de zona -o de varias zonas-, salvando de esta forma la dificultad o imposibilidad de construir un solo diagrama final con el millar de elementos, que, por otra parte, hubiera sido totalmente inasequible. Estos diagramas se interrelacionaban entre sí por los elementos comunes de sus bordes, por lo cual se cuidó especialmente la ordenación topográfica de los elementos en ellos.

En los procesos de reducción de relaciones redundantes y de periodización de los diagramas se observó también el valor temporal que conllevaba la colocación relativa del elemento a lo largo de las columnas verticales. La situación exacta se deducía por la relación directa de antero/ posterioridad y por la cronología absoluta, si el elemento la tenía, o por la relativa de su tipología. Cuando no era posible establecerla con alguno de estos criterios se creaban zonas temporales intermedias donde era probable, pero no seguro, que éste estuviera situado, pudiendo ascender o descender, si había nuevos datos, en la columna diacrónica hasta el tope impuesto por el elemento anterior o posterior con el que tuviera una relación directa.

En Santa Eulalia utilizamos por primera vez el término estructura -estratigráfica, no constructiva-, dándole un significado demasiado amplio que, en trabajos posteriores, matizamos de una forma más coherente introduciendo un nuevo concepto, el de edificio.

Sellamó estructura a la suma de elementos con una función concreta que atañe a toda una construcción -casa, mausoleo, iglesia-, superandola meramente estructural de las unidades de que se compone -muro, ventana, fachada, habitación-. Tal como empleamos este concepto en Sta. Eulalia, la estructura podía pertenecer a un momento sincrónico o a varios diacrónicos como resultado de múltiples reformas durante su vida, lo que, como veremos, resultó poco claro. Para resolver el problema de la estructura diacrónica se utilizó una numeración decimal: al número con que se denominaba la estructura en su conjunto se le añadía otro por cada cambio sufrido a través del tiempo, por ejemplo n.1, n.2, n.3, etc., sin que ello significara que los subconjuntos pertenecieran al mismo período cronológico. Por ejemplo el "mausoleo absidado", estructura 31, está compuesto por las unidades 31.1 y 31.2, paleocristianas; 31.3 y 31.4 , medievales; y 31.5 , moderna.

Actualmente pensamos que se debe restringir el significado de estructura, de modo que se tenga en cuenta no sólo que 
sus elementos y soluciones de continuidad mantengan una unidad estructural y funcional, sino también la etapa histórica a que pertenecen. De este modo surge un concepto nuevo, el de edificio, básicamente diacrónico, conformado por varias estructuras. A su vez, dentro de una estructura pueden diferenciarse etapas de obra o incluso etapas de uso, siempre que se puedan considerar "sincrónicas", en el sentido de pertenecientes a la misma función o al mismo período histórico; período que así ayuda a subdividir concretando más su cronología. Laadición o sustracción de estructuras-estoes, de conjuntos de elementos sincrónicosva a ir configurando el edificio tal y como se conocía en cada período -el edifício paleocristiano, el visigodo, el románico, ...-, hasta llegar a la construcción o al edificio final como hallegado a nosotros. De este modo se enriquece el significado estructural y temporal del análisis, frente a como se realizó en Sta. Eulalia, donde estructura siempre fue sinónimo de edificio.
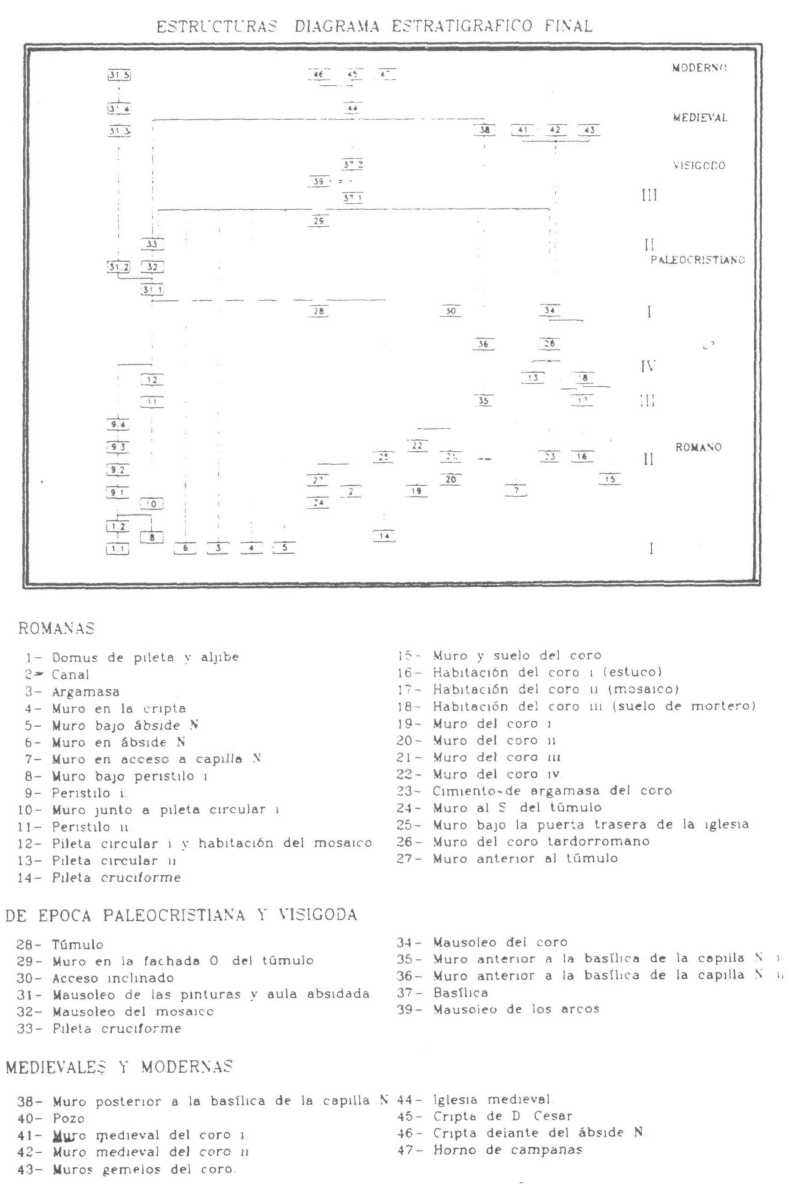

Fig.15.- Diagrama final de estructuras, con su indice y listado.
Sin embargo en el peristilo 9 -el patio columnado de una casa romana (Figs. 7-10)-, coinciden estructura y edificio, ya que los elementos añadidos sólo suponen reformas del mismo edificio, pertenecientes al período romano. Éstafue una estructura que entrañó gran dificultad aislar e interpretar dado que estaba prácticamente arrasada. Se conserva de ella sólo parte de la infraestructura del canal que lo rodeaba, que se encontraba por debajo del nivel de su suelo $\mathrm{y}$, en ocasiones, sólo improntas de las partes que lo componían. Aun así se ha podido reconstruir su evolución formada por las siguientes etapas:

9.1, preparación -dos elementos que amortizan una casa anterior-;

9.2, construcción del peristilo -41 elementos correspondientes al canal-;

9.3, restauración de 9.2 -reduciendo la anchura del canal y añadiéndole una capa de opus signinum, hormigón

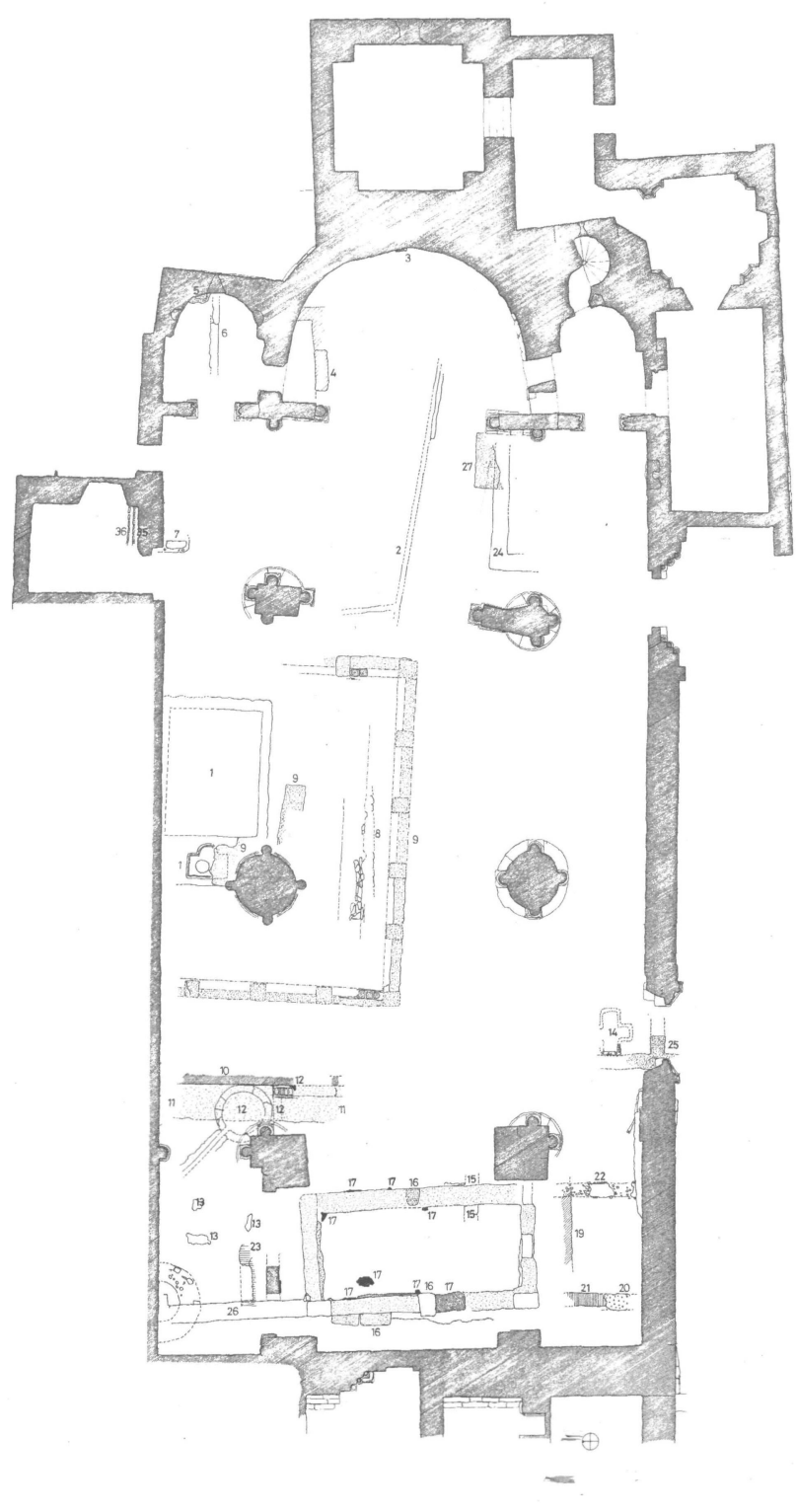

$\mathbf{A}$ 
hidraúlico, doce elementos-; y

9.4, segunda restauración -decoración del canal con mármol, 5 elementos (Fig .9)-

En este caso, según nuestra propuesta, tendríamos lo poco que queda de un edificio compuesto por una estructura con cuatro etapas de uso, que posiblemente estuvo en vida, desde la segunda mitad del s.I durante siglo y medio o poco más.

En SantaEulalia individualizamos 47 estructuras, algunas muy complejas y otras que debieron serlo, pero de las que sólo llegaron a nosotros uno o dos elementos. En este caso, a efectos de la lectura estratigráfica, uno o dos elementos pueden tener la misma importancia que una compleja estructura. Para sistematizar el análisis de las estructuras ideamos en Santa Eulalia la ficha de estructura (Fig. 13) y el diagrama de estructura -variante del de zona (Fig. 12)- instrumentos con los que las describíamos y periodizábamos apartir de la ordenación de los elementos que las componen; y el diagrama final de estructuras, con el que sintetizábamos las conclusiones cronológicas de modo quefueran fácilmente comprensibles -sustituyendo a un diagrama final de elementos que, como ya dijimos, habría sido imposible e inasequible por su complejidad (Fig. 15)-. Para este proceso aprovechamos la reducción de elementos a estructuras, ya que supone un proceso de síntesis basado en el análisis de las similitudes formales y funcionales. Complementario del diagrama de estructuras es el índice o listado de estructuras y los planos de etapas en que se numeran y dibujan los contornos de las estructuras diferenciadas (Fig. 16). Estos instrumentos facilitan la comprensión científica del proceso y permiten comprobar grosso modo su veracidad. A partir de ellos se puede iniciar, si es necesario, un proceso contrario para profundizar en la verificación hasta llegar al plano y diagrama de estructura, los croquis

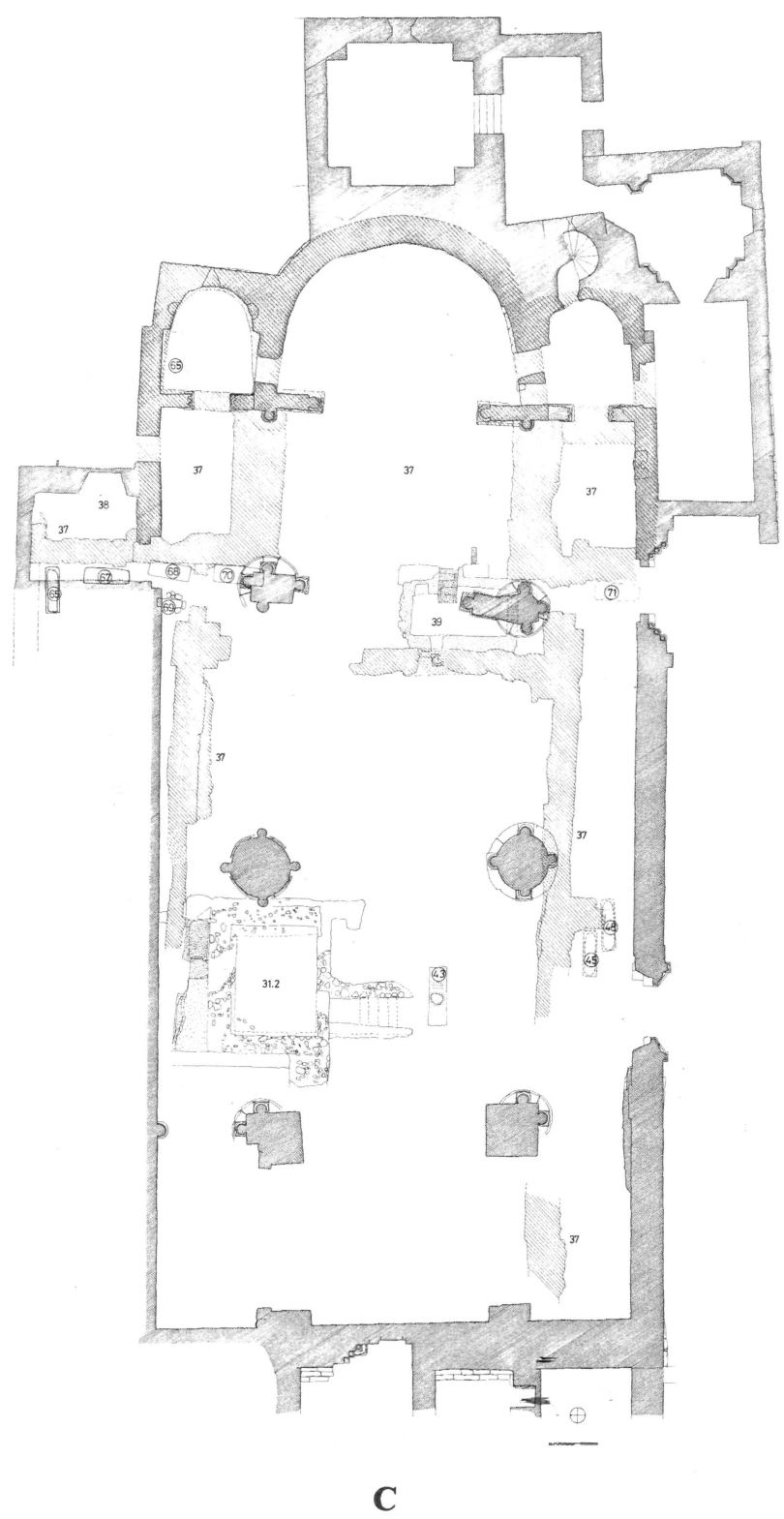

http://informesdelaconstruccion.revistas.csic.es 


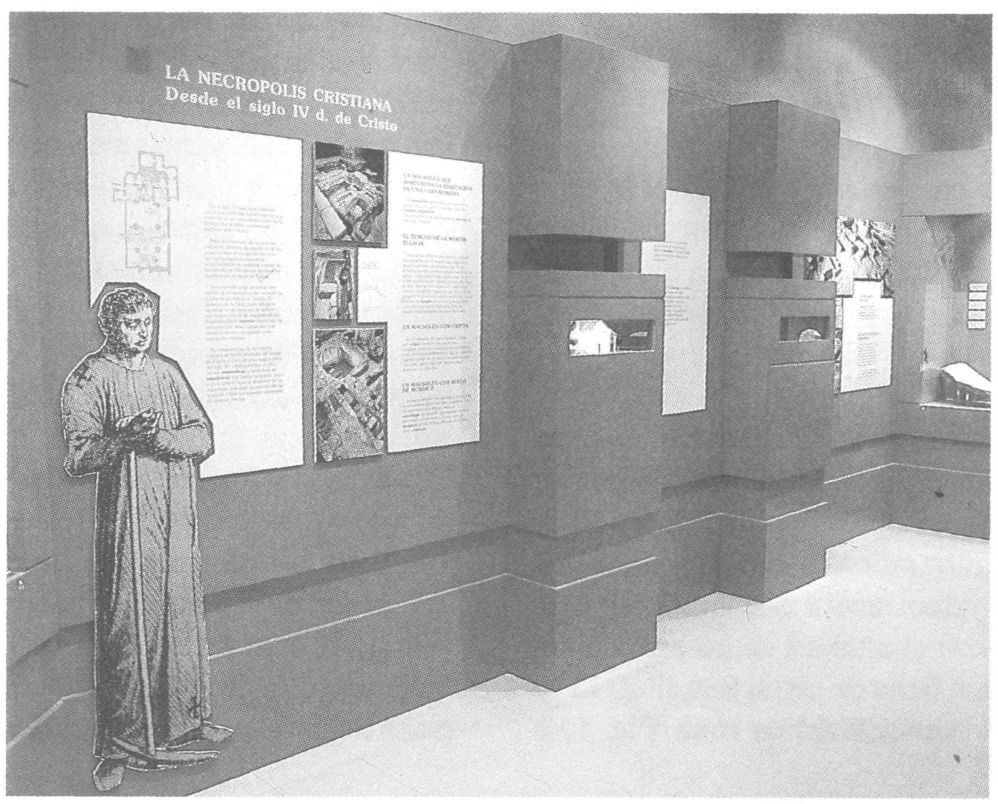

Fig.17.- La exposición del periodo "necrópolis paleocristiana" en el "centro de interpretación" previo a la visita a la excavación de Sta. Eulalia.

y diagrama de zona y las fichas y diagramas de elementos. En el proceso de trabajo de Sta. Eulalia falta, como instrumento fundamental, la planta y alzados generales de elementos, en que estén todos éstos individualizados por su contorno y su número.

La complejidad de la labor efectuada y la necesidad de unificar las diferencias de criterio obligaron a un proceso de trabajo peculiar, con reuniones diarias de los equipos en la discusión de problemas, zona por zona, en la redacción de los diagramas o en la definición de las estructuras en que intervenían varios equipos. Así se discutían los problemas, buscando un consenso entre todo el equipo, frente a la observación particular de un observador o la definición individual de cada miembro del equipo, y se objetivaban en lo posible las conclusiones.

Así, todos los elementos de que habíamos partido se sintetizaron al final en tres conjuntos constructivos fundamentales -haciendo abstracción de los medievales y modernos que corresponden a la iglesia en pie apenas analizada-, relacionados con períodos determinados:

A, estructuras domésticas de época romana;

$B$, necrópolis de época paleocristiana, $y$

$\mathrm{C}$, basílica utilizada en épocas paleocristiana, visigoda y mozárabe.

Las estructuras domésticas romanas (Fig. 16A) se han organizado en cuatro etapas consecutivas. A pesar de su dificultad de datación absoluta, estas etapas secuencian el tiempo histórico de época romana de una manera segura, dado que se basan en las relaciones temporales relativas descubiertas entre las estructuras. La primera ocupación del lugar, que debió ocurrir entre la fundación de la colonia
Emerita A ugusta -25 aC.- y el cambio de Era, está definida por muros aislados, algunos de ellos relacionados excepcionalmente con contextos arqueológicos que permitieron obtener la fecha límite de inicio. Por otra parte, uno de ellos, la pileta de baño Est. 1 (Figs. 6 y 7), conservaba en su interior un hallazgo cerrado perteneciente a su momento de destrucción, datado por sus cerámicas hacia el año $40 \mathrm{dC}$., fecha que se utilizó para diferenciar la primera de la segunda etapa romanas. El resto de períodos se fueron compaginando de acuerdo con las relaciones existentes entre las destruidas estructuras llegadas a nosotros, procurando siempre reducirlos al mínimo posible. Estos momentos se deben entender como secuencia cronológica de los restos conservados, de acuerdo con la lectura hecha de sus relaciones, más que como reales momentos históricos. Por lo tanto la idea final sobre la ocupación romana es que al menos se sucedieron consecutivamente cuatro domus o casas (Est 1,9,11,12). También se distinguieron aparentes diferencias topográficas, esto es la posibilidad de que, al menos en cierto momento, el actual solar de Sta. Eulalia estuviera ocupado por dos casas distintas, diferenciadas por la cercanía de dos peristilos o patios columnados (Est 9 y 11). Puede parecer que estas conclusiones -aquí muy resumidas- son muy pobres, pero también es cierto que ha sido la primera vez que se ha diferenciado una secuencia tal en la ciudad de Mérida, donde es seguro que se podrían diferenciar muchas secuencias parecidas que facilitarían el estudio evolutivo de la ciudad romana.

En un momento indeterminado, quizás en el s. III, el lugar dejó de habitarse $y$, tras una etapa de abandono, fue ocupado por una necrópolis ya en uso en el s. IV (Fig. 16B). Esta necrópolis pudo ser en un principio pagana, pero su importancia vino determinada por la construcción o la advocación de un mausoleo a la memoria de Eulalia, mártir 


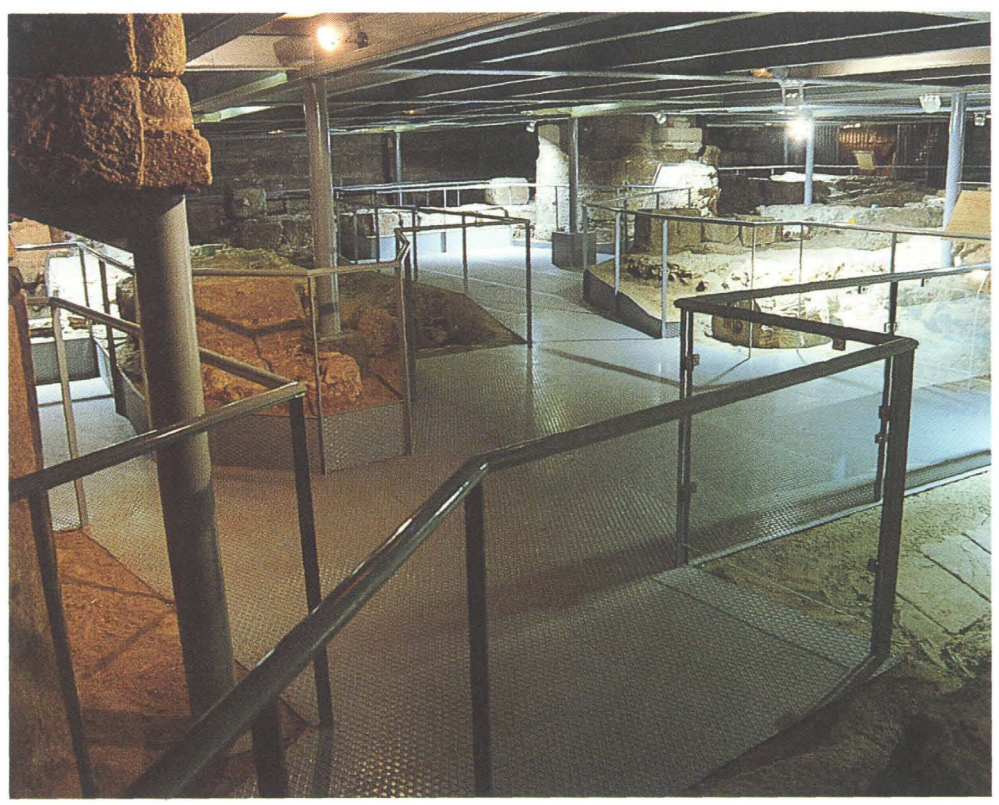

Fig.18.- Musealización de las ruinas de Sta. Eulalia de Mérida.

cristiana de comienzos del s. IV. Eléxito de esta necrópolis, debido al desarrollo del culto a la mártir, supuso la previa o simultánea destrucción de las casas anteriores. Suponemos muy verosímilmente que el mausoleo de Eulalia tuvo que ser la Est 28, ya que la inmediata basílica(Est 37) dedicada a su memoria se construyó de modo que su santuario tenía la misma forma y abrazaba el cimiento de este mausoleo. La construcción de la basílica y la utilización de su suelo, como lugar de enterramiento, supuso a su vez la parcial destrucción de la necrópolis previa. A esta destrucción se uniría posteriormente su expolioen épocaislámica buscando los mármoles de las tumbas, y la posterior ocupación cristiana que convirtió la basílica en iglesia. Por lo cual, de los cientos de sepulturas que debieron conformar la necrópolis paleocristiana, apenas han llegado a nosotros unas pocas : las conservadas en el lugar más sagrado, el santuario que antes había sido mausoleo de la mártir; las cubiertas por los cimientos corridos de las arquerías y los muros de la basílica; o las que estaban junto a estos cimientos, de las que se ha conservado su impronta o molde en las cales de la construcción -una solución de continuidadDe un importante mausoleo (mausoleo absidado, Est. 31.1, Figs. 11-13) sólo se ha conservado su cripta, ya que tuvo que ser demolido al construirse la basílica, aprovechándose ésta como un enterramiento privilegiado (Est.31.2), que finalmente fue vuelta a reutilizar en época moderna convirtiéndose en la cripta funeraria de un caballero santiaguista (mausoleo de las pinturas, Est.31.5).

De la basílica paleocristiana -restaurada y mantenida en uso en época visigoda y quizás mozárabe (Fig.16C)conocemos mejor la organización de su cabecera -con la cripta de los obispos -, a pesar del abandono que sufrió la basílica en época musulmana, por haber resistido hasta la recuperación cristiana y haber sido reutilizada para la organización de la cabecera de la actual iglesia, proceso al que ya nos referimos anteriormente. Conocemos los cimientos de las arquerías que separaban sus naves y la esquina NE. por lo que sabemos que su ancho fue de $30 \mathrm{~m}$, con una nave central de 15 metros.

Terminado el análisis histórico, se decidió conservar los restos y musealizarlos bajo el nuevo suelo construido en la iglesia. Para ello se habilitaron las salas de la antigua sacristía como centro de interpretación, donde se expone una selección de los materiales arqueológicos encontrados y se explica la evolución del yacimiento y la iglesia antes de visitar la nueva cripta museológica. El discurso expositivo aprovecha el esquema final conseguido con la lectura de paramentos, organizándose de este modo en las cuatro etapas descritas, que, con su sencillez, facilita la comprensión por parte del público no experto (Figs. 17 y 18).

\section{BIBLIOGRAFÍA}

ARCE, J. 1982: Mérida tardorromana (284-409 d.C.), Homenaje a Sáenz de Buruaga, Madrid, 209-226.

BROGIOLO, G. P. 1988: Archeologia dell'edilizia storica, Como.

BUENO ROCHA, J. 1987: Restos de época visigoda en la iglesia deSanta Eulalia de Mérida, II Congreso de Arqueología Medieval Española, Madrid, II, 321-330.

CABALLERO ZOREDA, L. (cood.) (1992): Sobre el análisis estratigráfico de construcciones históricas. Las experiencias de la Torre de Hércules de La Coruña, Santa EuTlalia de Mérida y S. Pelayo de Arlanza, III encuentros sobre Arqueologíay Patrimonio de Salobreña, Arqueología del monumento, Salobreña, octubre 
1992. Ayuntamiento de Salobreña, Universidad de Granada, Diputación Provincial de Granada y Junta de Andalucía (en prensa)

ID. 1992: ¿Visigodo o asturiano? Nuevos hallazgos en Mérida y otros datos para un nuevo "marco de referencia" de la arquitectura y la escultura alto-medieval en el N. y O. de la Península Ibérica, $39^{\circ}$ Corso di Cultura sull 'Arte Ravennate e Bizantine "Aspetti e problemi d'archeologia e arte in Lusitania, Asturia e Galizia tra Tardoantico e Medioevo", Universidad de Bolonia, 139-190. Con la aportación de P. Mateos.

ID. y MATEOS CRUZ, P. 1991: Excavaciones en Santa Eulalia de Mérida, I Jornadas de Prehistoria y Arqueología en Extremadura (1986-1990), Cáceres, Abril 1991, Extremadura arqueológica, 2, 525-546.

ID. e ID. 1992: Trabajos arqueológicos en la iglesia de Santa Eulalia de Mérida, Jornadas sobre Santa Eulalia de Mérida, Extremadura arqueológica, 3, 15-50.
ID. e ID. 1993: Santa Eulalia de Mérida. Excavación arqueológicay centro de interpretación, Guías arqueológicas, 3 , Mérida.

ID., ID. y FERNÁNDEZ DEL CASTILLO, H. (1993): Santa Eulalia de Mérida. Un "centro de interpretación" para su Arqueología y su Historia, conservar o restaurar. IV Simposio sobre actuaciones en el Patrimonio Edificado: conservar o restaurar, Barcelona, Diputación de Barcelona, Quaderns Cientifics $i$ Tècnics, 6 (en prensa).

HARRIS, 1991: Principios de estratigrafia arqueológica, Barcelona (1989)

MATEOS CRUZ, P. (1993): Excavaciones en la basilica de Santa Eulalia de Mérida, tesis doctoral, Facultad de Letras, Universidad Rovira i Virgili, Tarragona (manuscrito inédito).

MAYA SÁNCHEZ, A. 1992: Vitas Sanctorum Patrum Emeretensium, series latina, CXVI, Brepols, Turholt.

\section{Equipo Técnico}

Dirección: L.Caballero (Centro de Estudios Históricos. CSIC.) y P. Mateos (Escuela Española de Historia y Arqueología, Roma CSIC)

Análisis Arqueológico: M. Alba (Mérida); M. Alvarez (Univ. País Vasco); S. Feijoo (CSIC); M. Fernández Mier (Univ. Oviedo).

Colaboración Arqueológica:L.Caballero García; A. Fernández de Jauregui (UPV); A.I. Fernández(Univ. Oviedo); B. Gamo(Mus. Albacete); Mª A. Pedregal (Univ. Oviedo).

Dibujo: M.A.Nuñez (Arqueotecnia C.B.); J. Suárez; J. García-Villalva.

Fotografia: J.Latova (Actividades y Servicios Fotográficos)

Los trabajos se efectuaron durante los años 1990 y 1992, siendo subvencionados por la Junta de Extremadura. 